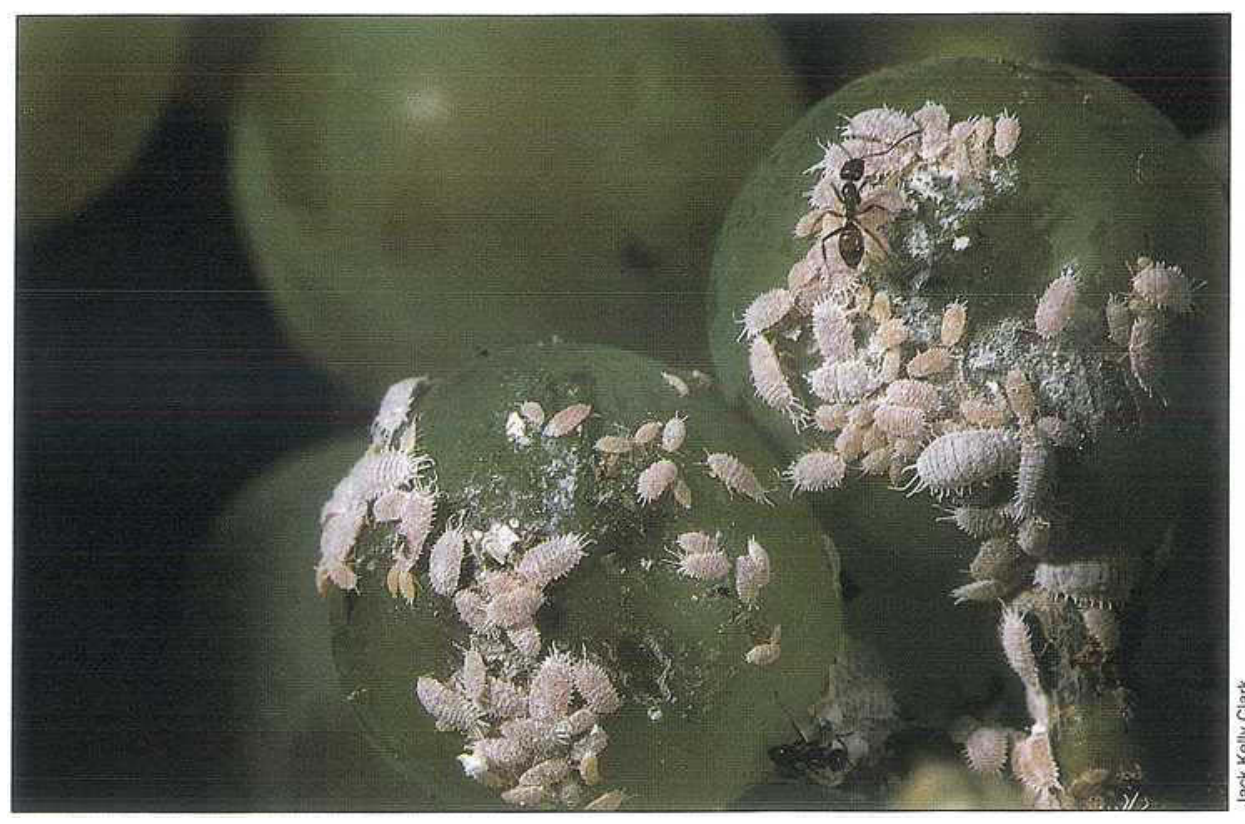

\section{To control mealybugs, stop honeydew-seeking ants}

\author{
Phil A. Phillips $\square$ Cindy J. Sherk
}

\section{Recent increases in obscure mea- lybug infestations in central-coast vineyards have been associated with Argentine ant activity. Mealy- bug infestations were reduced by controlling these honeydew-seek- ing ants in the spring, using chemi- cal treatments directed at the base of the vines. This control strategy avoids full coverage treatments disruptive to beneficials.}

Coastal wine grape vineyards in the Santa Maria and San Luis Obispo area have been faced with increasing mealybug problems since 1983. These are largely due to the obscure mealybug, Pseudococcus affinis Mask, firstidentified in aSan Luis Obispovineyard in 1987. Growers havebeenunable to prevent damage from this mealybug despite the use of dormant organophosphate and oil treatments in the winter, and foliar organophosphate treatmentsduring thegrowing season. These mealybug treatments have been jeopardizing coastal vineyard integrated pest management programs which depend heavily upon naturally occurring biological control agents: predaceous mites, chrysopids, coccinelids, spiders, parasitic hymenoptera, and a broad complex of other beneficials.

Associated with the initial heavy infestations of this mealybug and all subsequent infestations was the honeydew-feeding Argentine ant, Iridomyrmex humilis Mayr. As additional vineyards with damaging populations of obscure mealybug have been found, the Argentine ant has always been present and actively "working" the mealybugs, collecting their honeydew exudate. The ant has also been observed carrying about young mealybug crawlers.

Because the heavier, damaging populations of the obscure mealybug have only been found in association with the Argentine ant, it has become obvious that the real problem has been the presence of Argentine ant in the vineyards. The Argentine ant, along with other honeydew-feeding ant species, has long been known to aggravate mealybug populations and other honeydewproducing insect species by disrupting the natural biological controls on these species and by aiding in their dispersal.

\section{Background}

California Department of Food and Agriculture taxonomist Ray Gil first identified the obscure mealybug in 1987 from a sample taken in a San Luis Obispo vineyard. Infestations of obscure mealybug appear very similar to those of the more common grape mealybug, Pseudococcusmaritimus (Ehrhorn), invading the foliage and fruit clusters from their overwintering sites beneath the bark on the trunk and cordons.

The obscure mealybug overwinters in all developmental stages. It produces the typical honeydew and associated sooty mold problems on the grapeclusters and generally debilitates the vine. However, unlike the grape mealybug's preference for the more
Left: Obscure mealybugs tended by ants collecting honeydew exudate.

vigorous vines, the obscure mealybug indiscriminately attacks weaker vines as well as the more vigorous vines. Additionally, its body fluids are pale yellow to gray, unlike the orange-colored body fluids of the grape mealybug. Otherwise, the two mealybug species are indistinguishable to the casual observer.

A severeinfestation of obscuremealybug in coastal wine grapes was first observed by the senior author on weaker vines planted in a shallow soil area (above a rock outcrop) of a San Luis Obispo vineyard during 1986. This mealybug occurs commonly throughout California on oleander as well as other woody ornamentals.and is known as a minor pest of citrus in coastal California. It rarely produces economically important populations due to its associated natural enemies. It also occurs in Florida on avocados and on deciduous fruits in other countries such as New Zealand and Australia. In coastal California wine grape vineyards, the obscure mealybug shows a preference for Chardonnay and Pinot noir varieties. Populations are quite low in Sauvignon blanc.

\section{Methods}

A 600-acre vineyard in San Luis Obispo County was chosen for this study. Since 1985, this site has had an increasingly chronic problem with Argentine ant and obscure mealybug in most of its mixed varietal wine grape plantings. Within this vineyard, an 11acre cordon-trained Pinot noir block was selected for the study site.

The experiment consisted of three chemical treatments and a water check treatment directed at the base of each vine, each replicated six times within an area 10 rows wide by 36 vines long. A randomized complete block design was used to compensate for the typical vine-to-vine variation in Argentine ant colony size. We used one treatment of Diazinon AG 500 and two of Lorsban $4 \mathrm{E}$ (chlorpyrifos) at 21, 21, and 42 ounces of active ingredient per acre, respectively. Using a hand-held 2-gallon Hudson-type sprayer, these treatments and the water check were applied to the soil within a 12-inch radius around the vine trunk and to the trunk and its supporting stake up to 8 inches above the soil approximating $3 \%, 3 \%$, and $6 \%$ solutions, respectively. Treatments were applied on April 3, 1989, and again on June 6. (Although chlorpyrifos is not currently registered for use in California vineyards, we haveapplied for a special local needs registration. See comments in Results.) Each replicate consisted of 11 vines: 5 core vines, on which 
counts were made, with 3 buffer vines at each end providing protection from ant migration from adjoining replicates.

Depending on the intensity of activity and treatment dates, ant activity in each plot was assessed weekly or bi-weekly by counting the number of ants per minute trailing both up and down the vine trunk. Because the Argentine ant tends to trail beneath the loose bark on the trunk, each core vine was first prepared by removing a 6-inch-tall band of loose bark from around the trunk approximately 18 inches above the soil. This provided a sampling arena and facilitated counting the ants.

A push tack was used within this arena to mark the approximate initial trail location, facilitating location of weaker ant trails on subsequent sample dates. Any ants trailing on the outside of the supporting stake were also counted and included with the trunk count. Because the prevailing wind was from the northwest, the ants consistently located their trails on the east or leeward side of the vine orstake. Ant counts were taken between 10 a.m. and 1 p.m. each sample date, as cool early morning and late afternoon temperatures sharply depressed ant trailing. Pretreatment ant counts were made on each core vine trunk on March 31. As ant trail intensity varied considerably from plot to plot, treatments were assigned and blocked based on plot ranking for ant trail intensity. Starting with the four lowest trail intensity plots, each succeeding group of four plots with thenexthighest trail intensities received one each of the four treatments.

Obscure mealybug activity was monitored by following the activity of crawlers using double-sided transparent cellophane sticky tape. Sticky tape was wrappedaround each cordon 48 inches above the vineyard floor and within approximately 12 inches of the vine trunk. Before installation of the sticky tapes on March 31, any loose bark on the cordon was scraped away. This allowed for the tight adhesion of the tape to the smoothed cordon bark and forced any actively moving mealybug crawlers to crawl over the sticky upper surface of the tape where they were trapped.

Two vines per replicate were monitored bi-weekly in this fashion for a total of four tapes per replicate. Tapes were replaced biweekly. As the old tapes from each replicate were removed, they were placed on a 4-by-7-inch, blue file card. The tapes were counted within a week of collection and were kept refrigerated until that time to prevent desiccation and difficulty in reading.

On August 21, two weeks prior to harvest, the core vines were sampled for obscure mealybug activity on the foliage by assessing 10 basal cane leaves per vine for the presence or absence of mealybugs. In addition, five clusters per core vine were ran- domly chosen and sampled for the presence of mealybugs at this time. Clusters having mealybugs were rated for the intensity of infestation using the following scale: $0=$ none, $1=$ less than $25 \%$ by volume infested, $2=25 \%$ to $49 \%$ infested, $3=50 \%$ to $74 \%$ infested, and $4=75 \%$ to $100 \%$ infested. For each replicate, the severity of mealybug infestation was determined by multiplying the number of clusters in each rating category by the respective rating number and summing the products from each category. Fruit samples were also taken from the check and chlorpyrifos plots for residue analysis by the U.S.Department of Agriculture-Agricultural Research Service (USDA-ARS) Laboratory in Yakima, Washington.

On August 24, approximately 2 weeks before normal harvest, the plot was hand harvested and yield data were recorded for each replicate. The vineyard was pruned on January 29, 1990, and pruning weights for each replicate were also recorded as an indicator of vine growth during the test season.

\section{Results}

Ant trail intensity increased steadily in the spring through early July 1989 in the untreated check (fig. 1). After early July, trailing declined and continued to do so through the fall and winter, reaching a low in January through early March. Trailing activity declined sharply in all treatment plots shortly after the first application. Both the $3 \%$ Diazinon and the $3 \%$ Lorsban treatments had significantly fewer trailing ants than the check for approximately 6 weeks after treatment or for three out of five posttreatment counts before the ant activity rebounded. The 3\% Lorsban treatment had significantly fewer ants than the 3\% Diazinon treatment only on May 10, or for one out of the five posttreatment counts before the second application. The $6 \%$ Lorsban treatment had significantly fewer trailing ants than the check for all five of the posttreatment counts (after approximately eight weeks). The $6 \%$ Lorsban treatment was also more effective than the $3 \%$ Diazinon on three out of five posttreatment count dates, and more effective than the $3 \%$ Lorsban on one out of five posttreatment count dates.

After both the early April 3\% Diazinon and 3\% Lorsban treatments had lost effectiveness by mid-May, a second application of all treatments was made on June 6. Again, both of the $3 \%$ treatments significantly reduced Argentine ant trailing activity as compared to the water-applied check. Ant activity in the $6 \%$ Lorsban treatment remained at zero, and was only retreated to meet IR-4's protocol for possible future registration of Lorsban $4 \mathrm{E}$ for vineyard ant control. Ant activity remained significantly

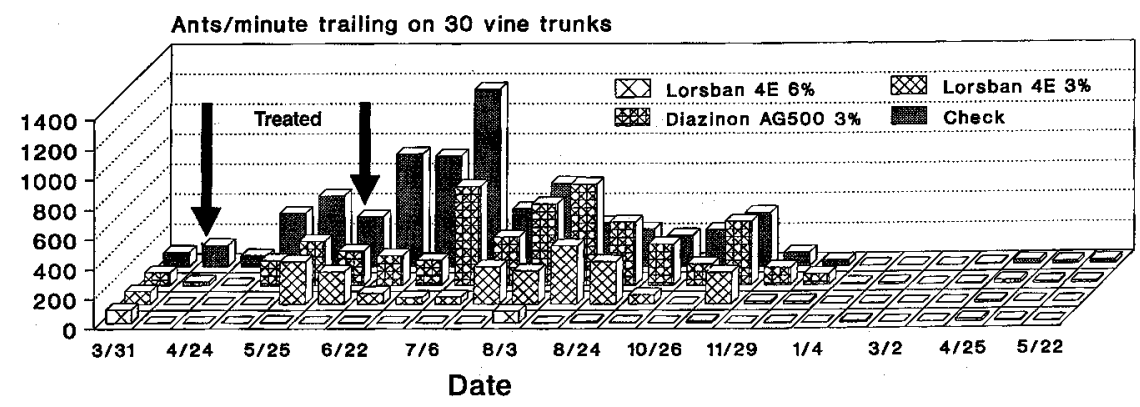

Fig. 1. Argentine ant activity on grapevine trunks from March 31, 1989 through May 22, 1990 in ant control plots.

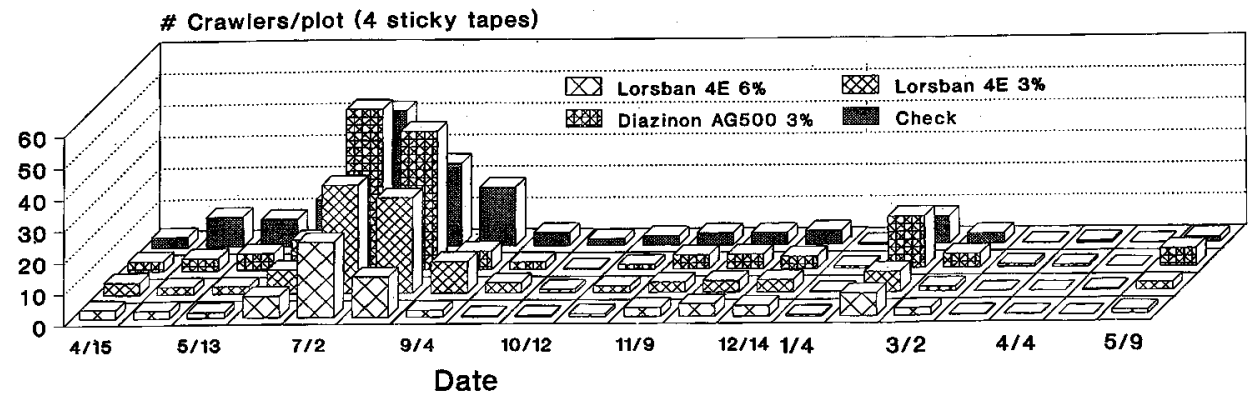

Fig. 2. Obscure mealybug crawler activity within the vine canopy from April 15, 1989 through May 9, 1990 in ant control plots. 
TABLE 1. Effects of varying levels of Argentine ant control on obscure mealybug crawler activity, infestation levels, vine yield, and pruning weight in a Pinotnoir vineyard

\begin{tabular}{lccccc}
\hline \hline Treatment & $\begin{array}{c}\text { Cumulative } \\
\text { ant counts }\end{array}$ & $\begin{array}{c}\text { Cumulativet } \\
\text { crawler } \\
\text { counts }\end{array}$ & $\begin{array}{c}\text { Mealybug } \\
\text { rating }\end{array}$ & Yield & Pruning weight \\
\hline no./minute & number & clusters & lbs & lbs \\
Check (water) & $1,190 \mathrm{a}$ & $160 \mathrm{a}$ & $70.2 \mathrm{a}$ & $57.8 \mathrm{a}$ & $15.8 \mathrm{a}$ \\
Diazinon AG 500 at 3\% & $757 \mathrm{ab}$ & $169 \mathrm{a}$ & $28.7 \mathrm{~b}$ & $55.1 \mathrm{a}$ & $16.8 \mathrm{a}$ \\
Lorsban 4E at 3\% & $352 \mathrm{bc}$ & $120 \mathrm{ab}$ & $19.5 \mathrm{bc}$ & $56.8 \mathrm{a}$ & $18.0 \mathrm{a}$ \\
Lorsban 4E at $6 \%$ & $19 \mathrm{c}$ & $76 \mathrm{~b}$ & $5.7 \mathrm{c}$ & $61.9 \mathrm{a}$ & $18.7 \mathrm{a}$ \\
\hline
\end{tabular}

*Average number of ants per five vine replicate trailing per minute per sample date summed over 17 sample dates from April 10 to December 14, 1989

tNumber of crawlers per tape per sample date summed over 20 sample dates from April 1, 1989 through May 9, 1990.

¥Severity rating established by multiplying the number of fruit in each rating category $(0-4)$ by the rating number of that category and summing the products from each category.

§Duncan's multiple range test for statistical means separation. Figures not showing a common letter are significantly different from one another at the $5 \%$ error level.

depressed in both the $3 \%$ treatments for approximately 4 to 5 weeks after treatment.

Due to vine-to-vine variability, the $6 \%$ Lorsban treatment led to statistically significant reductions in trailing ants for only 4 to 5 weeks after treatment. However, the total number of ants in this treatment remained well below those in the check through December. In fact, both Lorsban treatments were significantly less than the check with respect to cumulative ant counts for 1989 (table 1). In this regard, the 6\% Lorsban treatment also had significantly fewer accumulated ant counts than the 3\% Diazinon treatment. As ant activity picked upagain in April 1990, significant differences in ant activity reappeared, with both the $3 \%$ and $6 \%$ Lorsban treatments being significantly less than the check while the Diazinon treatment was intermediate in ant activity. These differences continued through the third week in May, when the experiment was terminated.

Mealybug crawler activity across the different treatments responded very similarly to the ant activity. As the mealybug crawler activity began to increase in late spring, thesticky tape trapcounts forcrawlers remained statistically similar for all treatments until mid-May (fig. 2). The sample taken between May 13 and June 4, 1989, showed a significant reduction in mealybug crawlers in both Lorsban treatments. With the single exception of the Diazinon treatment for thesample period October 1 through October 13 , only the $6 \%$ Lorsban treatment had significantly fewer crawlers than the check for the six sampling periods after June 4 and through October 26. When the accumulated crawler activity from April 1, 1989 through May 9, 1990, is examined, only the $6 \%$ Lorsban treatment had significantly fewer crawlers than the check (table 1).

On August 21, 1989, three days prior to an early harvest for champagne, obscure mealybug infestation levels on the foliage were significantly less than the check in all three ant treatments (fig. 3). With only $14 \%$ infestation, the $6 \%$ Lorsban treatment had the least percentage of foliage infested with mealybugs compared to $55.3 \%$ for the check. Cluster infestation ratings taken on the same day gave identical results, with all three treatments having significantly less severe cluster infestations than the check (fig. 3). Again, where the Argentine ant had been controlled to the greatest extent in the $6 \%$ Lorsban treatment, the amount of cluster infestation by theobscure mealybug was the least at only a 5.7 average severity rating. This was significantly less than the severity rating of 70.2 for the check.

When yields were taken at harvest on August 24, 1989, there was considerable plot-to-plot variation and no significant differences between treatments were detected. Pruning weights taken the following winter (January 29, 1990) also showed nosignificant differences between treatments, although there was a tendency for the treatments with fewer ants and mealybugs to have greater pruning weights (table 1 ).

Because chlorpyrifos is unregistered for use in California vineyards, we have applied for a special local needs registration to use Lorsban $4 \mathrm{E}$ for vineyard ant control.

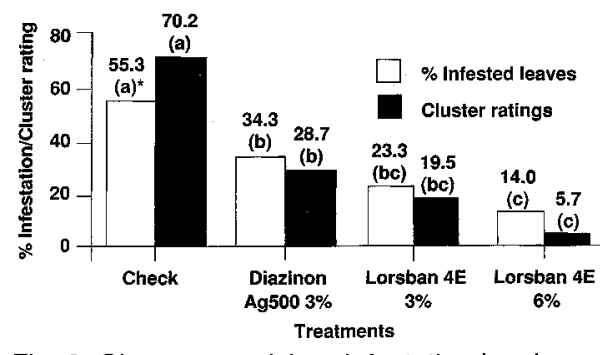

Fig. 3. Obscure mealybug infestation levels on August 21, 1989.

*Duncan's multiple range test for statistical means separation. Figures not showing a common letter are significantly different from one another at the $5 \% \mathrm{er}-$ ror level.
Fruit samples taken during harvest were sent frozen to the USDA-ARS laboratory in Yakima, Washington, where residue analysis for chlorpryifos, the active ingredient in Lorsban $4 \mathrm{E}$, was conducted by Ron Sell. No residues were found in the fruit as a result of using Lorsban $4 \mathrm{E}$ as a trunk treatment at either the $3 \%$ or $6 \%$ solution rates.

\section{Discussion}

Recent increases in vineyard infestations by the obscure mealybug have been associated with Argentine ant activity. We found that by controlling these honeydew-feeding ants, mealybug infestation levels can be significantly reduced. By reducing contamination of the fruit clusters by the mealybug and the honeydew it produces, marketable fruit quality can be increased.

Timing of ant control measures is crucial. Because mostant populations are at a low by the end of winter, treatments should be timed just as ants start actively foraging for food in the early spring, before they have had time to start rebuilding colony size. Ant nests are generally concentrated in the raised berm area beneath the vines, which is warmer and unshaded by vegetation. Therefore the targeted areas are the berm, vine trunk, and supporting stake. In addition, disking vegetation used for winter soil erosion control in between vine rows forces any ants nesting in bare spots within that vegetation area to move to the berm, where they can more easily be treated.

Not only do treatments at the vine base reach the ants where they are most concentrated in early spring, they also create a temporary chemical barrier preventing any surviving ants from gaining access into the vine canopy. This strategy avoids potentially disruptive broadcast ant treatments or full canopy treatments for the mealybugs, all of which are very disruptive of beneficial species and generally inadequate to control the pest mealybugs.

In this study, the use of Lorsban $4 \mathrm{E}$ as a $6 \%$ solution applied to the base of the vine and supporting stake and to the surrounding soil on the berm gave the best results. As Lorsban 4E is readily degraded by ultraviolet light, a second treatment to the exposed trunk/berm area may be necessary for satisfactory control under heavy ant pressure.

Phil Phillips is Area IPM Advisor and Cindy J. Sherk is Field Assistant, Ventura County.

The authors wish to thank Cathy Albert of California Polytechnic State University, San Luis Obispo, for her assistance with the mealybug crawler activity surveys; Jim Effird and Napolean Ruiz for donation of the plot site and their assistance; and Ron Sell for his invaluable residue analysis.

Use of trade names is for convenience only and in no way implies endorsement of the products mentioned. 